\title{
Dialogismo e a investigação de processos desenvolvimentais humanos
}

\author{
Katia de Souza Amorim \\ Maria Clotilde Rossetti-Ferreira \\ Universidade de São Paulo, Ribeirão Preto-SP, Brasil
}

\begin{abstract}
Resumo: Na elaboração de instrumental para compreender e investigar processos desenvolvimentais humanos, relacionais e situados, aproximamo-nos da noção de dialogismo. Procurando explicitar esta noção, realizou-se revisão bibliográfica, além de leituras de Bakhtin, aqui apresentadas. A análise levanta implicações teórico-metodológicas que, tanto apontam ao lugar da alteridade no ser e desenvolver-se humano, como indicam questões do fazer do pesquisador. Finalmente, apresenta-se um episódio de interação mãe-bebê, utilizando-se a concepção de dialogismo. A análise do caso aponta a necessidade de considerar o lugar do corpo nos processos de investigação, remete também à busca por noção de linguagem além do verbal e (re)conceituação da cultura enquanto prática discursiva.
\end{abstract}

Palavras-chave: Dialogismo. Linguagem. Cultura. Bebês.

\section{Dialogism and the investigation on human developmental processes}

\begin{abstract}
In the construction of a theoretical-methodological instrument, aimed to understand and investigate relational and situated human developmental processes, the notion of dialogism was reached. Seeking to make this notion more explicit, a bibliographical review and reading of bakhtinian propositions were carried out and presented in this study. Theoretical-methodological issues and practical implications were raised during the analysis, which appoint to issues like the place of the otherness in the self and human development. A series of issues concerning the research process is discussed. Finally, a mother-infant interactional episode is analyzed through the concept of dialogism. The analysis appoints to the need of considering the body in the investigation process. It also indicates the search for language notion that goes beyond its verbal dimension and re-conceptualization of culture as discursive practice.
\end{abstract}

Keywords: Dialogism. Language. Culture. Infants.

\section{Dialogismo y la investigación de procesos del desarrollo humano}

Resumen: La elaboración de instrumentos para comprender e investigar los procesos de desarrollo humano, relacionales y situados, nos acercamos de la noción de "dialogismo". En la búsqueda de una explanación para eso concepto, se realizó una revisión bibliográfica general, además de considerar en detalle la obra de Bakhtin. El análisis llevó a implicaciones teóricas y metodológicas que, además de mostrar el lugar de la alteridad en el ser y en el desarrollo humano, indicaran cuestiones de la práctica del investigador. Además, se presenta una situación real de interacción de una mama con su bebe, considerando el concepto de dialogismo. El análisis del caso muestra la necesidad de considerar el lugar del cuerpo en los procesos de investigación. Además, llega a la búsqueda de una noción de lenguaje más allá de la comunicación verbal y una nueva conceptualización de la cultura en cuanto una práctica discursiva.

Palavras clave: Dialogismo. Lenguaje. Cultura. Lactante. 


\section{Introdução}

Nos últimos dez anos, no campo da Psicologia do Desenvolvimento, fundamentando-nos em autores do enfoque histórico-culturais (Bakhtin, 1934/ 1981a, 1936/1997, 1929/1999; Valsiner, 1987; Vygotsky, 1978/1991; Wallon, conforme citado por Werebe \& Nadel-Brulfert, 1986), vimos elaborando a perspectiva da Rede de Significações (RedSig) (Amorim, Vitoria, \& Rossetti-Ferreira, 2000; RossettiFerreira, Amorim, \& Silva, 2000, 2004). O objetivo tem sido a construção de um instrumental que contribua para a investigação e compreensão dos processos de desenvolvimento humano.

Esses processos têm sido entendidos a partir do paradigma da complexidade, imersa que a pessoa está em uma malha de elementos intrinsecamente inter-relacionados, os quais contemplam aspectos das pessoas em interação, dos contextos específicos e da matriz sócio-histórica. E, por meio das dialéticas articulações entre aqueles elementos, pessoa e ambiente transformam-se como partes inseparáveis dentro de um processo de mútua constituição. As pessoas, assim, encontram-se imersas em, constituídas por e submetidas a uma malha de elementos/eventos; e, a um só tempo, ativamente os (re)constituem. Contribuem, dessa forma, para a circunscrição dos percursos possíveis de seu próprio desenvolvimento, do desenvolvimento das outras pessoas e da situação. Nesse sentido, a metáfora de rede torna-se útil, pois possibilita expressar o desenvolvimento das várias pessoas em interação e da situação como um todo, e não simplesmente de cada pessoa isolada das outras e do contexto, como tradicionalmente tem sido feito na área.

A rede configurada na ação de significar o mundo, o outro e a si mesmo, efetivada no momento interativo, é entendida como compondo um universo semiótico, no qual a diversidade de significações pode se mostrar mais ou menos ampla, revelando-se ora francamente diversa e polissêmica, ora bastante restrita. Em uma dada situação específica, a depender das significações possíveis, ocorre a atribuição pelo outro e por si mesmo, de papéis sociais e de formas específicas de coordenação de papéis (Oliveira \&
Rossetti-Ferreira, 1994, 1996), os quais favorecem certas possibilidades e limites de ações/emoções/concepções. Recursiva e dialeticamente, a emergência daquelas ações/emoções/concepções pode conduzir as pessoas à atribuição de novos sentidos, re-organizando a configuração da rede, a qual pode promover novas formas possíveis de comportamento.

Portanto, a articulação das diversas ordens de elementos altera-se continuamente, compondo novas configurações, as quais abrem uns e, simultaneamente fecham a possibilidade de outros percursos. Destaca-se, assim, a dinâmica dos processos e suas delimitações, já que as significações circunscrevem ações/ emoções/concepções em determinadas direções, mais do que em outras; promovem certas práticas sociais; delimitam zonas de possibilidades de atuação dos parceiros em interação. Assim, as configurações das redes atuam como impulsionadoras para determinadas direções e aquisições, ao mesmo tempo em que distanciam, impedem ou interditam outras. Atuam estabelecendo possibilidades e limites à situação, aos comportamentos e ao desenvolvimento das pessoas.

Dentre os potenciais percursos circunscritos, nem todos se atualizam. Sempre existem percursos que não serão percorridos, havendo possibilidades e capacidades que não têm chances de se efetivar. Ou, que têm sua aquisição iniciada, mas são perdidas diante de novas mudanças. Isso aponta ao desenvolvimento como um processo em que sempre ocorrem ganhos e perdas; e, ainda, que não se traduz em uma perspectiva evolutiva, com um sentido ascendente. Nesse sentido, a(s) rede(s) enquanto sistema(s) de circunscritor(es) do movimento do sistema organismo-meio, permite pensar as ações no tempo presente e em suas implicações futuras, fazendo com que o desenvolvimento seja considerado simultaneamente como determinado e indeterminado em vários domínios. Ocorre desta forma tanto a possibilidade de inovação, como certa previsibilidade das trajetórias desenvolvimentais.

Ainda, os processos desenvolvimentais só se tornam possíveis de serem compreendidos em sua qualidade relacional, situada e processual, dadas as 
relações às quais as pessoas se encontram articuladas, pertencentes e submetidas; e, ainda, do modo como se dão as contínuas (re)atualizações dessas relações. Finalmente, de que sua característica fundante é a intersubjetividade; isto é, a contínua e básica alteridade.

Partindo dessas concepções, ao explicitar as implicações teórico-metodológicas dessa alteridade, aproximamo-nos da noção de dialogicidade (Amorim, 2003; Rossetti-Ferreira, 2001). Porém, para nós, esta noção era vaga, havendo inconsistências em relação ao seu significado e às suas implicações na pesquisa. Buscamos, assim, explicitar aquele termo, o que foi feito a partir da análise de levantamento bibliográfico e de textos de autores que trabalham com essa noção.

Ainda, diante da análise empírica de crianças nos dois primeiros anos de vida, questionamos as noções de que a relação da criança com o outro e sua inserção no meio e na cultura se dão fundamentalmente com o desenvolvimento da fala intelectual e do pensamento verbal. Considerando-se que a relação eu-outro/eu-ambiente é fundante e está presente desde o nascimento, interrogamo-nos como se dariam os processos dialógicos, nessa faixa etária.

Esses dois tópicos - dialogicidade e dialogicidade nos primeiros anos de vida - têm sido trabalhados e são discutidos, nesse artigo. Para começar, iniciaremos pela questão do dialogismo.

\section{Processos desenvolvimentais dialógicos}

\section{Levantamento bibliográfico}

Buscando apreender como o termo dialogismo é utilizado, na literatura, realizamos levantamento bibliográfico (LILACS, SciELO e Web of Science), a partir dos termos dialógico(a)(s) e dialogical. Nas bases LILACS e SciELO, encontramos 75 resumos (1982-2007), com pico de publicações no novo milênio. Daqueles resumos, $40 \%$ tratam o dialogismo na área da saúde, 20\% da Psicologia e 20\% na Educação. Das 13 publicações da Psicologia, sete são do campo da Psicologia do Desenvolvimento (Colaço, 2004; Lyra, 2000, 2006, 2007; Lyra, Pantoja, Cabral,
Souza, \& Moutinho, 1995). As demais são provenientes da Psicologia Social, Psicologia Médica, Psicoterapia, Educação em Psicologia, dentre outras.

$\mathrm{Na}$ Web of Science, o termo é amplamente utilizado, havendo 33 resumos, somente no ano de 2002. O termo ali extrapola a Psicologia, abarcando também a Saúde, Antropologia, Educação, Comunicação, Geografia, dentre outras.

Nas várias bases, $50 \%$ das publicações não indicam as proposições de base. Dentre as que explicitam, verifica-se fundamentação em Paulo Freire, Bakhtin, Habermas, Martin Buber, Vygotsky, Hermans, Mead e na teoria relacional do construcionismo.

Na literatura nacional, o sentido mais usual ligase ao trabalho em saúde, destacando-se as relações entre pares, em busca por menor hierarquização e maior escuta do não-profissional (Barroso, Franca, Farias, \& Miranda, 2003). Outras publicações usam o conceito na metodologia. Há também sentidos ligados aos processos comunicativos. Destes, três atribuem o sentido de "continuidade dialógica", no processo comunicacional; dois abordam a "redução do diálogo" (em processos psicoterapêuticos ou em pacientes com psicopatologia). E um aborda a "ausência dialógica" (Araújo, 1997). A multiplicidade de sentidos também está presente nos resumos da Web of Science, tratando de forma dominante do "outro cultural" e do self dialógico.

Contrapondo-se à nossa expectativa inicial dialogia enquanto processo - na revisão, verificamos que o termo dialógico aparece qualificando processos, usualmente, como adjetivo ou qualidade, seja de uma intervenção, forma de relação ou abordagem metodológica. O termo qualifica posturas, atitudes e relações, que inclusive podem vir a ser ou não dialógicas. No geral, deparamo-nos com um universo atravessado por significados diversos. Daí perguntarmos qual desses significados seria coerente com a Rede de Significações? Qual deles possibilitaria explicitar teórico-metodologicamente a questão da alteridade, nessa perspectiva?

Nesse caminho, remetemo-nos a textos oriundos da revisão e de autores que trabalham, tradicional- 
mente, com a noção de dialogicidade, identificando autores, como Rommetveit (1992), Marková (1992), Wertsch (1992), Hermans e Kempen (1995), Hermans (2002), Valsiner (2000, 2002), Josephs (2002), Fogel (1993), Fogel, Koeyer, Bellagamba e Bell (2002), Lyra (2000), Lewis (2002) e Leiman (2002). Na maioria desses trabalhos, Bakhtin direta ou indiretamente representa um suporte à discussão. No entanto, apesar da base comum, verificam-se diferenças significativas na forma como o termo é usado na discussão dos processos, havendo recortes mais ou menos amplos, com contradições, divergências e lacunas. Diante disso, buscando interlocução da noção de dialogismo com a de relações pessoa-mundo, retomamos os textos de Bakhtin.

\section{Dialogismo em Bakhtin}

Neste artigo, será dado foco na discussão sobre processos dialógicos, não havendo intenção de apresentar o conjunto das proposições daquele autor. Porém, para essa tarefa, cumpre destacar que a abordagem de Bakhtin passa pelo lugar de onde ele fala; isto é, da lingüística, a partir da análise literária.

Ainda, cabe comentar que, na leitura de seus textos, emergem dificuldades para apreensão dos termos que ele utiliza. Usualmente, ele não os define com precisão, os diferentes termos aparecem de forma dispersa em seu material. Em alguns casos, há mudanças na descrição dos tópicos, havendo desencontros com relação aos significados. Tal forma de tratar do assunto pode ser derivada da característica de Bakhtin que, como afirmam Emerson e Holquist (Bakhtin, 1981b), não busca construir uma teoria. Segundo eles, a idéia que o motiva, em sua essência, seria oposta a qualquer formalização.

Finalmente, cumpre indicar que, em relação a algumas de suas obras, há um debate sobre a autoria, como do livro Marxismo e Filosofia da Linguagem (1929/1999), que é atribuída a ele e/ou Volochinov. Para um aprofundamento de questões centrais da obra de Bakhtin e do Círculo de Bakhtin e, particularmen- te, ao que se refere à problemática da autoria, o leitor deve se remeter a Faraco (2003) e Souza (2002).

Retomando a discussão de dialogismo e a busca da transposição dessa noção para o quadro da Psicologia de Desenvolvimento, cabe dizer que, apesar das possíveis dificuldades de articulação da linguagem literária e a Psicologia, o próprio Bakhtin dá indicações para esse caminho em seus livros (Bakhtin, 1929/1999; 1934/1981; 1936/1997), ao tratar da língua, linguagem, signo, discurso, sujeito e subjetividade.

A noção de dialógico, dialogismo ou dialogicidade aparece em seus textos através de diversas formas. Uma primeira relaciona-se ao que ele denomina "dialogismo interno da palavra" (Bakhtin, 1934/ 1981a). Nesse sentido, qualquer discurso encontra um objeto já sobrecarregado com valores, revelando uma multiplicidade de nomes, definições, julgamentos. Quem fala confronta múltiplas rotas, estradas, caminhos por que passou o objeto, havendo mesmo contradições internas. O objeto está, assim, amarrado através de pensamentos compartilhados, pontos de vista, julgamentos, inflexões de valor cheias de tensão, interconectando-se em complexos relacionamentos: juntam-se com algumas, afastam-se de outras, intersectam-se com outras ainda; harmonizam-se com alguns elementos e batem-se em dissonância com outros; esfregam-se contra milhares de fios dialógicos vivos, tecidos ao redor de um dado objeto de um enunciado.

Há, ainda, um desvelar de múltiplas vozes sociais, uma Torre de Babel de linguagens misturadas que o envolvem, a dialética do objeto estando interligada ao diálogo social que o atravessa. Desta forma, o objeto se encontra em uma bruma obscura, sendo, simultaneamente, iluminado pela luz das palavras aliens já faladas sobre ele. Entre a palavra e seu objeto, entre a palavra e o sujeito falante, existe um elástico ambiente do outro, palavras alien sobre o mesmo objeto, o mesmo tema. É nesse processo de interação viva em um ambiente específico que a palavra pode ser individualizada. A dialética do objeto está interligada com o diálogo social ao redor dele: vozes múltiplas dentre as quais a sua própria voz deve 
soar, sendo que essas vozes criam o necessário background para a sua própria voz, sem as quais sua voz não ressoa (Bakhtin, 1934/1981a).

Uma outra maneira de Bakhtin tratar dialogismo refere-se à "dialogicidade nos enunciados" (1936/ 1997), que propõe que a dialogicidade vai muito além da alternância de sujeitos falantes. Dentro disso, ele destaca a existência de enunciados anteriores, aos quais o próprio enunciado está vinculado por alguma relação. Assim, o próprio locutor é, em certo grau, um respondente, pois seu objeto de discurso não é objeto do discurso pela primeira vez nesse enunciado. O objeto já foi falado, controvertido, esclarecido, julgado de diversas maneiras. Quando escolhemos uma palavra, as tiramos de outros enunciados, nos fundamentamos neles, polemizamos com eles, refutamos, confirmamos, completamos, supomos conhecidos, contamos com eles.

De acordo com Bakhtin (1936/1997), nosso próprio pensamento nasce, forma-se e transformase sob o efeito da interação contínua e permanente com o pensamento alheio, com uma assimilação, mais ou menos criativa, das palavras dos outros. Estas palavras, no entanto, nem sempre são apropriadas: muitos enunciados resistem; outros soam estrangeiros, não sendo assimilados. Nossa fala está repleta de palavras dos outros, ecos e lembranças de outros enunciados e não podemos nunca determinar nossa posição sem correlacioná-la com outras posições. É no enunciado que diferentes pontos de vista, visões de mundo e tendências se cruzam, encontram-se e se separam. É daí que tomamos a palavra e a tornamos própria. Nesse sentido, a expressividade de uma enunciação nunca poderá ser compreendida e explicada até o fim, se se levar em conta somente o teor do objeto de sentido. A expressividade de um enunciado é sempre, em menor ou maior grau, uma resposta. Manifesta não só a relação com o objeto, mas também a relação do locutor com os enunciados dos outros.

Porém, para Bakhtin (1936/1997), o enunciado liga-se não só aos elos que o precedem, mas também, aos que lhe sucedem. Desde o início, elabora-se em função de uma eventual resposta, reação; dirigese a alguém; está voltado ao destinatário. O enunciado a quem respondo está já aqui, mas sua resposta está por vir. Enquanto falo, sempre levo em consideração o fundo aperceptivo em que minha fala será recebida: o grau de informação do outro, seus conhecimentos especializados, opiniões e convicções, preconceitos, simpatias, antipatias e intenções. Há uma antecipação da resposta.

Assim, a palavra é dirigida a uma resposta e não escapa da influência da palavra respondente que se antecipa, já que a orientação daquele que fala em direção ao ouvinte é uma orientação em direção a um horizonte conceitual específico. Dessa forma, diferentes pontos de vista, horizontes conceituais, sistemas para fornecer inflexões expressivas, vêm a interagir. $\mathrm{O}$ falante se esforça por conseguir uma leitura de sua própria palavra, em seu próprio sistema conceitual, dentro de um sistema conceitual alien do ouvinte. $\mathrm{O}$ falante penetra no horizonte conceitual do ouvinte e constrói seu próprio enunciado em território alien. Essa relação só é possível entre enunciados provenientes de diferentes sujeitos falantes. Pressupõe o outro social (Bakhtin, 1934/1981a).

Nesse processo, toda compreensão é prenhe de respostas e, de uma forma ou de outra, forçosamente, as produz: o ouvinte torna-se locutor. Dirigida a uma futura resposta, provoca uma resposta, antecipa-a e estrutura a si mesmo na sua direção. A réplica pode ser uma atitude responsiva muda, pode concordar ou discordar (total ou parcialmente), completar, adaptar, julgar; pode aprontar-se para executar um ato; pode ser uma compreensão responsiva de ação retardada (Bakhtin, 1936/1997).

No diálogo real, o respondente também funciona em via dupla: é estruturado no contexto do diálogo, que consiste de enunciados próprios e aliens. $\mathrm{O}$ enunciado se dirige a alguém, é provocado por algo, persegue uma finalidade qualquer; ou seja, é um elo na cadeia de comunicação verbal, no interior de uma dada esfera da realidade humana. Desta forma, de acordo com Bakhtin, quando se analisa uma oração isolada, tirada de seu contexto, encobrem-se os indí- 
cios que revelariam seu caráter de dirigir-se a alguém, a influência da resposta pressuposta, a ressonância dialógica que remete aos enunciados anteriores do outro, as marcas atenuadas da alternância dos sujeitos falantes que sulcaram o enunciado por dentro.

Finalmente, há a “dialogização das linguagens" (Bakhtin, 1934/1981a). Nesse sentido, a linguagem (língua nacional) é plural, com uma multiplicidade de vozes sociais, que estabelecem uma variedade de inter-relacionamentos. Essa pluralidade se encontra estratificada em dialetos e linguagens sociais (linguagens das reuniões, linguagem familiar, cotidiana, sócio-política; dos jargões profissionais; de geração e de idade; de autoridade; do dia; oratória, publicitária, científica, jornalística, literária, dentre outras.). Cada uma carrega temas e pontos de vista específicos de mundo, com significados e valores filosóficos e morais, havendo uma variedade de mundos concretos, de sistemas de crenças, circunscritos sócio-culturalmente, cada um com seu próprio tom diferente, cada qual propondo-se como "linguagem de verdade", igualmente relativa, reificada e limitada.

O discurso, no entanto, é vivo e vive nos modos sociais, devendo ser visto de formas contraditórias e como mundos de múltiplas linguagens. Estas não se excluem, mas intersectam-se de maneiras diversas, com uma inter-animação em uma variedade de formas. Nesse processo, ocorre a co-existência de contradições sócio-ideológicas entre o presente e o passado; entre diferentes épocas do passado; entre diferentes grupos sócio-ideológicos do presente; entre tendências, escolas, círculos e assim por diante, com o encontro e a disputa entre pontos de vista distintos. Estes podem estar justapostos, mutuamente suplementando ou contradizendo-se; algumas linguagens falham em se desenvolver, algumas morrem, enquanto outras florescem em linguagens autênticas. Dado o jogo vivo, a linguagem se encontra em um histórico e ininterrupto processo de tornar-se, formando socialmente novas linguagens.

Para o autor, não há unidade de estilo, unidade de linguagem e unidade de uma pessoa individual realizando-se nessa linguagem. Uma mesma pessoa não tem uma única linguagem, mas múltiplas linguagens. $O$ falante não fala em uma dada linguagem; mas através de linguagens.

A forma concreta do enunciado, porém, pertence ao sujeito do discurso (daquele que fala, com suas intenções, propósitos), não podendo existir fora dessa forma. $\mathrm{O}$ intuito, elemento subjetivo do enunciado, entra em combinação com o objeto de sentido (com o qual há relação valorativa) para formar uma unidade indissolúvel. Porém, ele tem fronteiras, marcadas pela situação concreta, pelas circunstâncias, que emanam de alguma esfera da atividade humana e refletem as condições específicas e finalidades da dada esfera. São determinadas pelos parceiros e intervenções anteriores, pela posição social, pelo tipo de relacionamento, pelo título, posição, categoria de quem fala e de quem ouve. Dependem da importância conferida pela e à idade do destinatário e de acordo com a situação do próprio locutor e da relação de poder entre eles.

Assim, as formas de manifestação do signo são entremeadas pela organização social de tais indivíduos e pelas condições em que a interação acontece. E, para que o objeto pertencente a qualquer esfera da realidade entre no horizonte social do grupo e desencadeie uma reação semióticoideológica, é indispensável que ele esteja ligado às condições sócio-econômicas essenciais do referido grupo, as quais envolvem de alguma maneira as bases de sua existência (Bakhtin, 1929/1999).

Desta forma, a linguagem vive nas bordas entre o seu próprio contexto e o do outro; reside nas bordas entre alguém e outro. A palavra é sempre de alguém mais. Torna-se nossa somente quando o falante a popula com suas intenções, inflexão. Nesse sentido, estudar a palavra ignorando o impulso que se estende além dela, é tão sem sentido quanto estudar a experiência psicológica fora do contexto daquela vida real à qual foi direcionada (Bakhtin, 1934/1981a).

\section{Dialogismo enquanto processo}

Considerando essas proposições, afirmamos que dialogismo não pode ser confundido com interação 
(ao menos, com a noção de interação que tem sido tradicionalmente proposta, em que se pressupõe que os parceiros em interação "fazem algo juntos" e obedecem a alguns critérios como proximidade física, gestos dirigidos ao outro, direcionamento do olhar e/ ou postural, recíprocos (Baudonnière, 1988; Camaioni, 1980; Eckerman, 1979). Tampouco, pode ser confundido com qualidade de interações, as quais podem inclusive não acontecer, no sentido de não se constituir como processos com o outro. O sentido proposto por ele, e assumido aqui, implica um sentido mais substantivo, enquanto processos da relação com o outro, que regulam o viver e o desenvolver-se. Refere-se à alteridade básica (Coelho Jr., 2003), ao modo de funcionamento da existência do ser humano, à formade-ser-no-mundo.

Como Barros (2002) afirma, essas noções propiciam uma compreensão mais radical da alteridade, permitindo entender o outro de uma maneira original, o outro sendo referido não como alguém que está fora de mim, que é estranho a mim, mas como alguém que me constitui, que contribui para o processo de construção de um eu que não me pertence integralmente e que somente existe a partir do olhar do outro.

Wold (1992) afirma que pontos de vista dialógicos (com destaque para a alteridade) não são novos. James, Mead, Vygotsky, Buber, Habermas vêm todos, de longa data, buscando explicitá-los. Abordar o dialogismo no estudo de processos psicológicos representa a busca por uma metáfora que contemple estudar e compreender o desenvolvimento humano como inerentemente social, cultural e histórico (Wold, 1992). Nesse sentido, a opção pela investigação embasada na dialogicidade (tal como proposto por Bakhtin) implica em assumir teias de pressuposições que destacam a natureza social do ser humano e sua inserção na coletividade cultural (Rommetveit, 1992). Implica em evitar a armadilha da dicotomia e antinomia indivíduo-sociedade (Hermans \& Kempen, 1995).

Nesse sentido, muitos autores têm buscado explicitar as questões que tratam do dialogismo e da intrínseca relação da pessoa-meio. Em vários traba- lhos, certos pontos têm sido considerados como centrais com relação àqueles processos, alguns dos quais são aqui apontados:

(1) Estudar o dialogismo não significa acompanhar processos que envolvam "duas" pessoas. Como apontado e discutido anteriormente, dada a natureza social, cultural e histórica do ser humano, os processos dialógicos envolvem múltiplos outros sociais através dos quais e com os quais se criam elos e entrelaçamentos referentes ao que as vozes individuais podem dizer. Isso significa dizer que uma voz fala através de outras vozes ou de um outro tipo de voz. Isto é, que uma voz individual fala simultaneamente com a voz coletiva. Assim, as ações individuais são ao mesmo tempo expressões das ações dos grupos aos quais se pertence, da cultura na qual se nasceu e desenvolveu.

Além disso, processos dialógicos extrapolam o processo interativo face-a-face, a alteridade se dando através de diferentes formas. Transpondo as idéias de Bakhtin para a Psicologia, Hermans e Kempen (1995) descrevem várias maneiras como se dão as relações dialógicas: (a) direta: troca ativa e intersubjetiva, na comunicação imediata e direta envolvendo dois ou mais parceiros, co-construindo ações e interações; (b) indireta: processos dialógicos que acontecem mesmo quando a pessoa está sozinha, pois ela não está nunca só e agindo como indivíduo isolado, mas continuamente em dialogicidade, em uma sociedade na qual outras pessoas estão indiretamente co-construindo a ação individual, como, por exemplo, através das ferramentas (ação mediada); (c) através da imaginação: quando um parceiro não está presente (por exemplo, na leitura ou redação de um texto), em que se tem um diálogo com questões e respostas imaginadas dos outros; (d) finalmente, há o dialogismo dentro da noção de self dialógico (Hermans, 2002). Fundamentando-se em proposições de William James (que aponta às diferenças entre o "eu" e o "mim") e se apropriando da noção de polifonia de Bakhtin, Hermans afirma que a pessoa é constituída por uma dinâmica multiplicidade de "eus", cada um representando vozes específicas que se relacionam, se 
alternam e que estabelecem relações diversas de dominância e de poder. Como ele afirma, o self está envolvido em oposições, concordâncias, discordâncias, contradições e integrações. Haveria, assim, uma multiplicidade de posições entre as quais acontecem relacionamentos dialógicos, o eu tendo a possibilidade de mudar de uma posição para outra diferente e, até mesmo, oposta. Haveria, assim, relações dialógicas entre posições diversas, resultando em um self complexo, narrativamente estruturado. Hermans, partindo do estudo da Personalidade, promove importantes avanços ao apontar para um self visto não mais como monológico, mas como múltiplo.

Apresentamos aqui, com maior detalhe, a visão de self dialógico, pois esta representa importante derivação das proposições bakhtinianas, com grandes repercussões no desenvolvimento de vários estudos. Porém, é importante frisar que temos algumas questões com relação a essa proposição. Uma primeira deve-se à não elucidação da questão relativa às condições que fazem com que uma voz específica emerja no self dialógico. Isto é, como é que as alternâncias dos eus acontecem? Considerando o lugar de onde investigamos - Psicologia do Desenvolvimento - o modo por que se dá a alternância, dominância e transformação das vozes, nos processos desenvolvimentais, mostra-se da maior relevância.

Essa mesma questão tem sido apontada por Valsiner (2002), ao afirmar que a multiplicidade de vozes promove uma dinâmica, mas não garante que o desenvolvimento do ser humano aconteça e nem aponta para o modo como ele acontece. Nesse sentido, o autor tem buscado explicitar teoricamente os mecanismos de base que podem levar, ou não, ao desenvolvimento. Sua meta tem sido discutir como transformações são organizadas, ocorrem e/ou deixam de ocorrer. Nesse sentido, para o autor, discutir desenvolvimento a partir do self dialógico, implica em dizer que o foco teórico está direcionado à dinâmica dos relacionamentos, ao invés de focalizar nos componentes do sistema (eus). Porém, Valsiner trilha em uma perspectiva que trata de vozes internalizadas, que se auto-organizam e auto-regulam, através de coordenação dinâmica e hierárquica, que operam como um sistema auto-catalítico, um sistema onde seus próprios componentes (suas múltiplas vozes) reproduzem-se, enquanto lidam com a novidade da experiência, constituindo a base para a transformação daquele self.

Esse aspecto da proposta de Valsiner (2002), também presente na de Hermans (2002), representa nosso segundo ponto de reserva à proposta de self dialógico, já que o "outro" acaba por se delimitar em torno das múltiplas vozes apreendidas de outros anteriores. É como se, com o desenvolvimento, esses múltiplos outros internalizados adquirissem certa autonomia em relação ao ambiente, sendo que contexto e interlocutor - alteridades contínuas no devir de nossas vidas - perdessem destaque, distanciando-se ou até mesmo podendo desaparecer em importância.

(2) Retornando à discussão sobre alguns pontos centrais aos processos dialógicos, entende-se que uma segunda questão diz respeito ao fato de que, no processo dialógico, não existe uma mensagem que circula, mas há um encontro de significados. Um indivíduo não origina comunicação, mas participa dela, o processo devendo ser entendido no nível relacional. O significado muda na medida em que a interação se desdobra; é criado na medida em que acontece, sendo seu processo e resultado parcialmente não previsíveis. Nesse sentido, o significado lingüístico é compreendido como aberto e dinâmico, sendo dialogicamente constituído no estabelecimento e desenvolvimento da intersubjetividade.

(3) Outro aspecto refere-se à idéia de que a dialogicidade considera como intrínsecas as concretas condições em que alguém entra em contato com o outro. Nesse sentido, o processo é considerado como dependendo da posição que os interlocutores ocupam. Isso tem levado vários autores a assumir a noção de posicionamento, proposta por Harré e Van Langenhove (1999), que tem sido construída através do e utilizada fundamentalmente no estudo de adultos e envolvendo circunstâncias conversacionais concretas. Em função disso, e dadas às características de alguns sujeitos dos nossos estudos (bebês), não tem 
sido possível assumir tal proposição. Entende-se como complicado falar em posicionamento, se este é entendido como a construção discursiva de histórias pessoais que torna as ações pessoais inteligíveis e relativamente determinadas como atos sociais, e dentro das quais cada membro da conversação tem localizações específicas; se para aqueles autores, as posições indicam que o que as pessoas fazem tem um caráter intencional (dirigido para algo além de si mesmo) e normativo (submetido a normas e julgamentos), submetidas à ordem moral local, aos sistemas de direitos, deveres e obrigações.

Assim, para lidar com a questão da posição, temos assumido a noção de papel/contra-papel e de coordenações de papéis (Oliveira, 1988; Oliveira \& Rossetti-Ferreira, 1994). O modo como esse termo é proposto por Oliveira diverge da tradicional e criticada noção de papel social. Tendo como sustentação autores como Vygotsky, Wallon, Mead e Bakhtin, a autora propõe que a relação de recíproca constituição que se estabelece entre indivíduo e meio dá origem a situações sempre novas e únicas, criadas pela interação dos parceiros. Assim, desde o nascimento, a criança é colocada em uma matriz social geradora de significados que são atribuídos, assumidos, negados e recriados na própria interação, pelo confronto de papéis presentes no processo de atribuição de sentidos a si mesmo, ao outro e à situação (Oliveira, Guanaes, \& Costa, 2004).

(4) Para Bakhtin (Bakhtin, 1929/1999), a palavra é um fenômeno ideológico por excelência e o modo mais puro e sensível de relação social, em que formas ideológicas mais gerais de comunicação semiótica são reveladas. A palavra acompanha e comenta todo ato. $\mathrm{E}$, ainda, todas as manifestações da criação - todos os signos não-verbais - banham-se no discurso e não podem ser nem totalmente isoladas e nem totalmente separadas dela. No entanto, apesar do status que ele atribui à palavra, o autor afirma que isso não significa que ela possa suplantar qualquer outro signo. Segundo ele, nenhum dos signos específicos é inteiramente substituível por palavras. Nem sequer existe um substituto adequado para o mais sim- ples gesto humano. Todavia, embora nenhum desses signos seja substituível por palavras, cada um deles, ao mesmo tempo, se apóia nas palavras e é acompanhado por elas. Mais ainda, todas as manifestações verbais estão, por certo, ligadas aos demais tipos de manifestação e de interação de natureza semiótica (como a mímica, a linguagem gestual, os gestos condicionados, dentre outras.).

Nos processos dialógicos, portanto, as "falas", as "vozes" não se restringem às conversações verbais. Nesse sentido, Hermans e Kempen (1995) falam de ações dialógicas.

Esse conjunto de tópicos impeliram-nos, ainda, a pensar nas implicações teórico-metodológicas, especialmente naquelas relacionadas ao concreto fazer da pesquisa.

\section{Dialogismo no fazer do investigador}

Dentre as várias questões possíveis de serem aqui exploradas, alguns aspectos serão destacados. Um primeiro é que, ao se investigar um certo objeto de estudo, este já contém um "dialogismo interno", estando sobrecarregado por valores, definições, julgamentos de valor. $\mathrm{O}$ tema já emerge entremeado por vários elos e fios do diálogo social, através de vozes múltiplas, dentre as quais, a voz do pesquisador deve soar. Dentro dessa polifonia, cabe ao pesquisador buscar identificar as vozes mais relevantes e se posicionar com relação a elas, deixando explícito o lugar de onde fala.

Um segundo aspecto diz respeito à relação pesquisador-pesquisado. Nesse sentido, assumindo a noção de dialogismo, ao se lidar com os sujeitos participantes do estudo, entende-se que aquela relação não é neutra, mas se faz a partir dos múltiplos enunciados aos quais se está vinculado. Implica, assim, que pesquisador assim como o sujeito participante carreguem um conjunto de pressuposições, embates e expectativas, que vão estar marcando o seu falar/ fazer e a própria estruturação do estudo. Aquelas vão estar marcando, também, as leituras que fazem da situação, a partir de seu sistema conceitual, considerando sempre o sistema conceitual do outro. Ainda, a 
antecipação de respostas e/ou dos comportamentos diante das situações contribuem para circunscrever a ação/fala de cada um, naquele contexto, relativo àquele tema específico.

Esses elementos fazem com que o lugar do pesquisador deva ser claramente considerado, alçando-o enquanto sujeito agente da pesquisa. Também, aponta como premente o registro das condições de produção e das circunstâncias da pesquisa. E, ainda, a análise sobre o modo como se dá a coordenação de papéis entre pesquisador e pesquisado, considerando-se de forma concreta a pergunta formulada e o contexto de investigação, pois esses aspectos vão estar ativamente contribuindo para constituir e co-construir os dados obtidos.

Como diz Wallon, 1941 (conforme citado por Werebe \& Nadel-Brulfert, 1986), não há observação que seja uma cópia exata e completa da realidade, já que não há observações sem escolhas, sendo essas escolhas determinadas pelas relações que existem entre o tópico investigado e as expectativas e hipóteses do pesquisador. Não nos é possível escapar dessa situação. Assumir isso, no entanto, não implica em propor um relativismo total, onde tudo seja possível. Apesar de que as coisas são ditas pelo pesquisador, ele não pode dizer qualquer coisa, já que há elementos nos eventos, comportamentos, nos aspectos históricos, organizacionais e físicos, dentre outros que contribuem para circunscrever as possibilidades e os limites da interpretação.

Nesse sentido, a meta é o pesquisador compreender e explicitar o próprio papel, seus limites, possibilidades e implicações. Caso contrário, o risco é que não será possível desvincular resultados de pressupostos. Como afirmam Maturana e Varela (1995), os pesquisadores devem agir de maneira a ver-se a si próprio, como um olho que olha ao próprio olho.

Finalmente, outra implicação a ser discutida refere-se à análise de dados propriamente dita. Ao se analisar uma frase (entrevista), um comportamento (vídeogravação) ou documento, o pesquisador não pode se restringir à sua manifestação "objetiva", de- vendo ir além do sentido estrito do que se fala/faz/ está escrito, abarcando elementos do contexto e da história em que o dado emerge. A busca é por apreender os múltiplos significados que o envolvem e que com ele estão em harmonia e embate, articulando-se, repetindo, transformando-se.

Esses vários aspectos discutidos sobre processos dialógicos acabaram por nos guiar na análise de episódios interativos envolvendo bebês, como apresentamos a seguir.

\section{O estudo de processos dialógicos nos primei- ros anos de vida}

O estudo de processos desenvolvimentais nos primeiros anos de vida tem sido uma das nossas frentes de pesquisa, fonte de uma série de questões e questionamentos. Especificamente, ao se considerar o dialogismo como intrinsecamente central ao modo de funcionamento da existência do ser humano, a pergunta que recorrentemente nos colocamos é como ocorrem tais processos, nos primeiros anos de vida? Se o dialogismo está ligado à forma-de-ser-no mundo, tais processos teriam que ser considerados desde o nascimento, mesmo que a criança ainda não adquiriu capacidade de uso da linguagem verbal, do uso da palavra.

A questão da linguagem no primeiro ano de vida é encontrada no estudo de vários pesquisadores, como Fogel (1993), Braten (1992) e Trevarthen (1993). Braten (1992), por exemplo, trata do protodiálogo ou da proto-conversação. Ainda, segundo Hermans e Kempen (1995), autores como Clarke-Stewart, Perlmutter e Friedman (1988), propõem a noção de pseudo-diálogo na interação mãe-bebê, em que a mãe promove a troca de turnos com a criança, como se o bebê assumisse seu papel, como em uma conversação real. A proposição deriva da idéia de que o bebê é muito novo para se engajar em um diálogo real.

Para Hermans e Kempen (1995), no entanto, essa pressuposição é expressão da visão tradicional que iguala diálogo com conversação verbal e que não 
há diálogo que preceda o desenvolvimento da linguagem verbal. Contrapondo-se a isso, os autores referem que há posições como a de Fogel (1993), que propõe o diálogo pré-lingüístico. Segundo essa, pressupõe-se que exista um self dialógico prélinguiístico, distribuído entre corpo e ambiente, pois a percepção constitui-se como uma co-percepção do self e do meio. Como um ser corporificado (embodied), a criança aprende a se comunicar tanto com os outros, como com ela própria, enquanto que, ao mesmo tempo, é capaz de realizar discriminações perceptuais entre ela e os outros.

Porém, investigações nossas com bebês nos fizeram levantar questionamentos com relação a essas concepções. As questões apareceram na pesquisa de doutorado (Amorim, 2002), que investigou a concretude de elementos sociais, políticos, históricos, econômicos e culturais no aqui-agora das situações, e que contribuem para circunscrever os processos desenvolvimentais. Tal estudo foi feito acompanhando-se os processos de adaptação e eventos de adoecimento, durante freqüência de bebês (cinco a treze meses) à creche.

Transcendendo o objetivo da tese, mas intrinsecamente relacionado a ele, a análise dos casos levou à observação de que não só os bebês agem de acordo com as regras e concepções culturais do seu grupo, como, em um curto espaço de tempo, modificam seu comportamento de acordo com os diferentes adultos (familiares, educadoras, técnicas da creche), de suas concepções e práticas junto às crianças. Mais ainda, era possível verificar que, desde muito cedo, os bebês ativamente negociam sentidos e intenções, nas suas diversas relações. Assim, os bebês não parecem participar do diálogo de forma primária (proto) ou falsa (pseudo); nem mesmo parecem se encontrar numa fase anterior à linguagem. A análise de novos episódios nos levaram recolocar a questão do dialogismo nessa faixa etária e a apontar para a reconsideração de alguns aspectos teórico-metodológicos, conforme discutimos abaixo, a partir da análise de um caso.

\section{O caso de Dirceu ${ }^{I}$}

$\mathrm{O}$ recorte selecionado se refere a interações entre o bebê Dirceu e sua mãe. O trecho faz parte do Banco de Dados do Projeto Processos de adaptação de bebês à creche (Rossetti-Ferreira, Amorim, \& Vitória, 1994), que estudou 21 bebês (quatro-treze meses), seus familiares e educadoras, durante freqüência à creche, no ano de 1994. A situação foi registrada a partir de entrevistas (mães, educadoras), além de gravações em vídeo dos três primeiros meses de freqüência à creche.

Dirceu (13 meses) é um bebê que anda, porém não fala. A cena ocorre no segundo dia de freqüência da criança à creche. Em função disso, dadas as regras da creche, Dirceu permanece acompanhado pela mãe. No episódio, a mãe está sentada em um colchão, colocado no chão. Dirceu está em pé, próximo a ela e à cena de vídeo, observamos:

De forma repetida, por curtos momentos, Dirceu afasta-se da mãe, voltando-se rapidamente a se reaproximar dela, indo ao seu colo, abraçando-a, aparentemente em um jogo lúdico, como que "fugindo" de uma outra criança encarada como potencialmente capaz de pegar um objeto que está em sua mão.

Nesse ir ao e sair do colo, em uma das vezes, ao sair do colo da mãe, sua mão esbarra no cabelo dela, ficando com alguns fios de cabelo presos em seus dedos. À medida que se afasta da mãe, sua atenção, anteriormente dirigida à outra criança, volta-se à própria mão e aos fios de cabelo presos nela. Daí, pára, vira-se e anda na direção da mãe, que continua sentada, mas conversando com uma pessoa ao lado. Dirceu pára bem em frente a ela. Como ela está sentada no colchão, seu rosto se encontra na mesma altura do rosto da criança. Assim, ele a olha, estica e dirige a mão à mãe, a qual fica bem na altura e direção do rosto dela. A mãe, que falava com alguém, volta-se ao filho e o olhar dos dois se cruzam. Nesse

\footnotetext{
${ }^{1}$ Todos os cuidados éticos de pesquisa foram tomados. As famílias dos bebês e as educadoras foram esclarecidas quanto aos objetivos do estudo e concordaram em participar do mesmo. O projeto foi aprovado pelo Comitê de Ética em Pesquisa.
} 
movimento e encontro, Dirceu olha para a mãe, ele sorri e passa a mão no rosto dela, em forma de carinho, que se estende do alto do rosto à parte inferior do queixo. Depois, ele se afasta, procurando, ele próprio, retirar os fios de cabelo presos em seus dedos.

Análise do episódio nos leva a dizer que Dirceu entra em ativa troca de significados com o outro (mãe), apesar de não ser capaz de fazer o uso de signos verbais (palavras). Nessa situação, sem qualquer palavra entre mãe e filho, a criança constrói um enunciado: diante de um problema (fios de cabelo emaranhados em seus dedos) (o enunciado é provocado por algo), reporta-se à mãe (o enunciado se dirige a alguém), para que ela retire os fios de cabelo de seus dedos (há uma intenção; o enunciado persegue uma finalidade, antecipando uma possível resposta). Mais ainda, o enunciado é construído de maneira apropriada às formas culturais: a mãe é a pessoa a quem se reporta em caso de dificuldades, atribuindo a ela o papel de solucionar problemas. Simultaneamente, no jogo de papéis, ele se coloca no lugar de quem precisa de ajuda. Assim, reconstitui enunciados anteriores, construídos na sua história, dentro de contextos específicos.

Porém, esses papéis/contra-papéis representam uma das múltiplas formas de ambos se relacionarem. Assim, no momentâneo aqui-agora do re-encontro de mãe e filho, provavelmente facilitado pela própria disposição física-espacial de um em relação ao outro, ao estender o braço (que fica na altura do rosto da mãe) e no encontro de olhares, novos sentidos emergem, dentre os quais um é colocado em figura, fazendo com que a criança assuma um novo papel/contra-papel, reconstituindo a ação. Dirceu passa então a ser o filho carinhoso, que demonstra afeição por ela. Portanto, no momento interativo, o significado muda, desdobra-se. O resultado previsível não é atingido. As ações, os enunciados e a relação caminham por percursos diversos do esperado.

A interpretação nos leva a dizer que Dirceu apreende e expressa significados; que assume e atri- bui determinados papéis a ele e a outros, os quais são construídos socialmente; que ele ativamente reformula os sentidos, que circulam dentro de situadas relações. Nesse processo, entra em coordenações de papéis, antecipa respostas e modula o seu comportamento em função delas; ele se relaciona dialogicamente com os outros. Tal análise nos leva a contrapor à noção de pseudo (falso) diálogo, já que a nossa interpretação é de que o dialogismo está presente, fazendo com que Dirceu trave um verdadeiro diálogo com sua mãe. Também, a nos contrapor à noção de diálogo prélingüístico, já que nos parece que Dirceu não se apresenta numa fase anterior à linguagem, mas está imerso nela, expressando-se através de algumas de suas variadas formas.

Portanto, para exploração desse campo, entendemos como necessário reconsiderar alguns pontos. O primeiro refere-se à noção de linguagem. Para compreendermos a relação do bebê com o outro social e apreendermos suas dialógicas relações, devemos nos afastar de propostas que tomam o adulto (oral, verbal) como o padrão de medida do ser criança, de propostas as quais projetem na criança a representação do ser adulto (Carvalho, 1983). Entre adultos e crianças não existem apenas semelhanças, mas também diferenças e essas diferenças traduzem a peculiaridade da "condição de ser criança" e não algo negativo dessa condição (Pino, 2003). Desta forma, a linguagem teria que ser pensada de forma a extrapolar o aspecto verbal. No estudo da criança pequena, particularmente, é fundamental reconhecer outras linguagens para a relação, apreensão e expressão de significações, no sentido de podermos considerar, de fato, os bebês como sendo inerentemente sociais, culturais e históricos. Nesse sentido, como afirmam Herman e Kempen (1995), deve-se explorar o papel do corpo (embodiment) com relação à ação dialógica. Ainda, como afirma Leiman (2002), temos que buscar a linguagem na mútua responsividade. Uma linguagem que resgate o outro, em relação ao qual nossa posição se (re)coloque; uma noção de linguagem que seja considerada de forma relacional e situada. 
Porém, se entendermos que bebês apreendem e expressam aspectos culturais sem utilizarem signos internalizados, decorre a necessidade de se reconceituar e utilizar a noção de cultura em estudos de desenvolvimento. A cultura não pode mais ser considerada como uma entidade com existência independente, ou como um conjunto de regras e normas abstratas aprendidas ao longo da socialização. A noção de cultura, ainda, deve perder sua característica de exterioridade. Ela deve ser concebida dentro da noção de matriz sócio-histórica (Amorim \& Rossetti-Ferreira, 2004), como tendo concretude no aqui-agora.

Caso essas revisões e modificações na forma de compreender e investigar processos desenvolvimentais no primeiro ano de vida não se dêem, corremos o risco de continuarmos a fazer da Psicologia a busca do indivíduo, perdendo a noção de que ele é, de que ele existe-no-mundo através do outro. Torna-se, assim, necessária uma nova forma de conceber a pessoa, o signo, a linguagem e a cultura, de modo a articularmos as profundas lacunas construídas nas propostas tradicionais que tratam da relação entre o indivíduo e a sociedade.

\section{Referências}

Amorim, K. S. (2002). Concretizações de discursos e práticas histórico-sociais, em situações de freqüência de bebês à creche. Tese de doutorado não-publicada, Universidade de São Paulo, Ribeirão Preto, SP.

Amorim, K. S. (2003). Dialogia (e significação) no primeiro ano de vida [CD-ROM]. In Anais do Encontro Nacional da ABRAPSO, 12.

Amorim, K. S. \& Rossetti-Ferreira, M. C. (2004). A matriz sócio-histórica. In: M. C. Rossetti-Ferreira, K. S. Amorim, A. P. S. Silva \& A. M. A. Carvalho (Orgs.), Rede de significações e o estudo do desenvolvimento humano (pp. 94-112). Porto Alegre: Artmed.

Amorim, K. S., Vitoria, T., \& Rossetti-Ferreira, M. C. (2000). A rede de significações como perspectiva para a análise do processo de inserção de bebês na creche. Cadernos de Pesquisa, 109, 115-144.
Araújo, H. V. (1997). A dimensão retórico-ideológica na saúde pública (materno-infantil) no período juscelinista. Dissertação de mestrado não-publicada, Universidade Federal da Paraíba, João Pessoa, PB.

Bakhtin, M. (1981a). Discourse in the novel (C. Emerson \& M. Holquist, Trans.). In M. Holquist (Ed.), The dialogic imagination: Four essays (pp. 259422). Austin: University of Texas Press. (Original publicado em 1934)

Bakhtin, M. (1981b). Preface (C. Emerson \& M. Holquist, Trans.). In M. Holquist (Ed.), The dialogic imagination: Four essays (pp. xiii-xv), Austin : University of Texas Press. (Original publicado em 1934)

Bakhtin, M. (1997). Estética da criação verbal. São Paulo: Martins Fontes. (Original publicado em 1936)

Bakhtin, M. (1999). Marxismo e filosofia da linguagem. São Paulo: HUCITEC. (Original publicado em 1929)

Barros, Z. (2002). O olhar constituinte do outro: Reflexões metodológicas à luz de Bakhtin. Recuperado em 23 maio 2005, de http:// www.cienciassociaisja.hpg.ig.com.br/ ooutrodebakhtin.

Barroso, M. G. T., Franca, I. S. X., Farias, F. S. A. B., \& Miranda, K. C. L. (2003). Aconselhamento em HIV/ AIDS como prática educativa interdisciplinar: Reflexões e possibilidades. Jornal Brasileiro de AIDS, 4(1), 23-27.

Baudonnière, P. M. (1988). L'évolution des compétences à communiquer: Chez l'enfant de 2 à 4 ans. Paris: PUF.

Braten, S. (1992). The virtual other in infant's mind and social feelings. In A. H. Wold (Ed.), The dialogical alternative: Towards a theory of language and mind (pp. 77-97). Oslo: Scandinavian University Press.

Camaioni, L. (1980). L'interazione tra bambini. Roma: Armando Armando. 
Carvalho, A. M. A. (1983). O desenvolvimento da criança. Pediatria Moderna, 18, 269-280.

Clarke-Stewart, A., Perlmutter, M., \& Friedman, S. (1988). Lifelong human development. New York: Wiley.

Coelho Jr., N. E. (2003). Da intersubjetividade à intercorporeidade: Contribuições da filosofia fenomenológica ao estudo psicológico da alteridade. Psicologia USP, 14(1), 185-209.

Colaço, V. F. R. (2004). Processos interacionais e a construção de conhecimento e subjetividade de crianças. Psicologia: Reflexão e Crítica, 17, 333-340.

Eckerman, C. O. (1979). The human infant in social interactions. In R. R. Cairns (Ed.), The analysis of social interactions: Methods, issues and illustrations (pp. 163-178). New Jersey: Lawrence Erlbaum.

Faraco, C. A. (2003). Linguagem \& diálogo: As idéias lingüísticas do círculo de Bakhtin. Curitiba: Criar.

Fogel, A. (1993). Developing through relationships: Origins of communication, self and culture. Hertfordshire: Harvester Wheatsheaf.

Fogel, A., Koeyer, I., Bellagamba, F., \& Bell, H. (2002). The dialogical self in the first two years of life. Embarking on a journey of discovery. Theory \& Psychology, 12, 191-205.

Harré, R., \& Van Langenhove, L. (1999). The dynamic of social episodes. In R. Harré \& L. Van Langenhove (Eds.), Positioning theory: Moral contexts of intentional actions (pp. 1-13). Oxford: Blackwell.

Hermans, H. J. M. (2002). The dialogical self as a society of mind. Theory \& Psychology, 12, 147-160.

Hermans, H. J. M., \& Kempen, H. J. G. (1995). Body, mind and culture: The dialogical nature of mediated action. Culture \& Psychology, 1, 103-114.
Josephs, I. E. (2002). 'The hopi in me': The construction of a voice in the dialogical self from a cultural psychological perspective. Theory \& Psychology, 12, 161-173.

Leiman, M. (2002). Toward semiotic dialogism: The role of sign mediation in the dialogical self. Theory \& Psychology, 12, 221-235.

Lewis, M. C. (2002). The dialogical brain. Contributions of emotional neurobiology to understanding the dialogical self. Theory \& Psychology, 12, 175190.

Lyra, M. C. D. P. (2000). Desenvolvimento de um sistema de relações historicamente construído: Contruibuições da comunicaçäo no início da vida. Psicologia: Reflexão e Crítica, 13, 257-268.

Lyra, M. C. D. P. (2006). O Modelo EEA para a investigação da emergência e desenvolvimento da comunicação e do self: Bases conceituais e fundamentos teórico-metodológicos. Estudos de Psicologia (Natal), 11(1), 25-33.

Lyra, M. C. D. P. (2007). O Modelo EEA: Definições, unidade de análise e possíveis aplicações. Psicologia: Reflexão e Crítica, 20, 87-95.

Lyra, M. C. D. P., Pantoja, A. P. F., Cabral, E. A., Souza, M. de, \& Moutinho, A. K. (1995). A produção vocal do bebê: Construção partilhada pela díade. Psicologia: Teoria e Pesquisa, 11, 1-6.

Marková, I. (1992). On structure and dialogicity in Prague semiotics. In A. H. Wold (Ed.), The dialogical alternative: Towards a theory of language and mind (pp. 45-63). Oslo: Scandinavian University Press.

Maturana, H., \& Varela, F. (1995). A árvore do conhecimento. São Paulo: Psy II.

Oliveira, Z. M. R. (1988). Jogos de papéis: Uma perspectiva para análise do desenvolvimento humano. Tese de doutorado não-publicada, Universidade de São Paulo, Ribeirão Preto, SP. 
Oliveira, Z. M. R., Guanaes, C., \& Costa, N. R. A. (2004). Discutindo o conceito de "jogos de papel": Uma interface com a teoria do posicionamento. In M. C. Rossetti-Ferreira, K. S. Amorim, A. P. S. Silva \& A. M. A. Carvalho (Orgs.), Rede de significações e o estudo do desenvolvimento humano (pp. 69-80). Porto Alegre: Artmed.

Oliveira, Z. M. R., \& Rossetti-Ferreira, M. C. (1994). Coordination of roles: A theoretical: Methodological perspective for studying human interactions. In N. Mercer \& C. Coll (Orgs.), Teaching, learning and interaction: Vol. 3. Explorations in socio-cultural studies (pp. 217221). Madrid: P. del Rio

Oliveira, Z. M. R. \& Rossetti-Ferreira, M. C. (1996). Understanding the co-constructive nature of human development: role coordination in early peer interaction. In J. Valsiner \& H. Voss (Eds.) The structure of learning processes (pp. 177-204). Norwood, NJ: Ablex.

Pino, A. (2003). As marcas do humano: A questão das origens da constituição cultural da criança na perspectiva de Lev S. Vigotski. Tese de Livre-docência não-publicada, Universidade Estadual de Campinas, Campinas.

Rommetveit, R. (1992). Outlines of a dialogically based social-cognitive approach to human cognition and communication. In A. H. Wold (Ed.), The dialogical alternative: Towards a theory of language and mind (pp. 20-44). Oslo: Scandinavian University Press.

Rossetti-Ferreira, M. C. (2001). Significação e dialogia na perspectiva da Rede de Significações. Manuscrito não publicado, Universidade de São Paulo, Ribeirão Preto, SP.

Rossetti-Ferreira, M. C., Amorim, K. S., \& Silva, A. P. S. (2000). Uma perspectiva teóricometodológica para análise do desenvolvimento humano e do processo de investigação. Psicologia: Reflexão e Crítica, 13, 281-293.
Rossetti-Ferreira, M. C., Amorim, K. S., \& Silva, A. P. S. (2004). Rede de significações: Alguns conceitos básicos. In M. C. Rossetti-Ferreira, K. S. Amorim, A. P. S. Silva \& A. M. A. Carvalho (Orgs.), Rede de significações e o estudo do desenvolvimento humano (pp. 23-34). Porto Alegre: Artmed.

Rossetti-Ferreira, M. C., Amorim, K. S. , \& Vitória, T. (1994). A creche enquanto contexto possível de desenvolvimento da criança pequena. Revista Brasileira de Crescimento e Desenvolvimento Humano, 4(2), 35-40.

Souza, G. T. (2002). Introdução à teoria do enunciado concreto do círculo Bakhtin/Volochinov/ Medvedev (2a ed.). São Paulo: Humanitas.

Trevarthen, C. (1993). The self born in intersubjectivity: An infant communicating. In U. Neisser (Ed.), The perceived self (pp. 121-173). New York: Cambridge University Press.

Valsiner, J. (1987). Culture and the development of children's actions. Great Britain: John Wiley.

Valsiner, J. (2000). Making meaning out of mind: Selfless and self-ful dialogicality. International Conference on the Dialogical Self, 1. Nijmegen, Holanda.

Valsiner, J. (2002). Forms of dialogical relations and semiotic autoregulation within the self. Theory \& Psychology, 12, 251-265

Vygotsky, L. S. (1991). A formação social da mente. São Paulo: Martins Fontes. (Original publicado em 1978)

Werebe, M. J. G., \& Nadel-Brulfert, J. (1986). Henri Wallon. São Paulo: Ática.

Wertsch, J. V. (1992). A dialogue on message structure: Rommetveit and Bakhtin. In A. H. Wold (Ed.), The dialogical alternative: Towards a theory of language and mind (pp. 65-76). Oslo: Scandinavian University Press.

Wold, A. H. (1992). Introduction. In A. H. Wold (Ed.), The dialogical alternative: Towards a theory of language and mind (pp. 1-18). Oslo: Scandinavian University Press. 
Artigo recebido em 22/08/2007.

Aceito para publicação em 08/05/2008.

As autoras agradecem a Mara Ignez Camposde-Carvalho, Tatiana de Souza e Joseane Bomfim, pela leitura crítica do texto e pelas sugestões de modificações, e ainda, à FAPESP pelo financiamento dos projetos temático e individual (pós-doutorado e projeto de pesquisa).

Endereço para correspondência:

Profa. Dra. Katia de Souza Amorim. Universidade de São Paulo. Faculdade de Filosofia, Ciências e Letras de Ribeirão Preto. Departamento de Psicologia e Educação. Av. Bandeirantes, 3900. CEP 14040-901. Ribeirão Preto-SP, Brasil.. E-mail: katiamorim@ffclrp.usp.br

Katia de Souza Amorim é Professor Doutor da Faculdade de Filosofia, Ciências e Letras de Ribeirão Preto da Universidade de São Paulo.

Maria Clotilde Rossetti-Ferreira é Professor Titular da Faculdade de Filosofia, Ciências e Letras de Ribeirão Preto da Universidade de São Paulo. 